\title{
Investigating bilingual processing: the neglected role of language processing contexts
}

\author{
Yan Jing $W_{u^{1}}$ and Guillaume Thierry ${ }^{1,2 *}$ \\ School of Psychology, Bangor University, Bangor, UK \\ Economic and Social Research Council Centre for Research on Bilingualism in Theory and Practice, Bangor University, Bangor, UK
}

Edited by:

Sonja A.E. Kotz, Max Planck Institute

Leipzig, Germany

Reviewed by:

Judith F. Kroll, Penn State University,

USA

David William Green, University

College London, UK

\section{*Correspondence:}

Guillaume Thierry, School of

Psychology, University of Wales, LL57

2AS Bangor, UK.

e-mail: g.thierry@bangor.ac.uk
How do the two languages of bilingual individuals interact in everyday communication? Numerous behavioral- and event-related brain potential studies have suggested that information from the non-target language is spontaneously accessed when bilinguals read, listen, or speak in a given language. While this finding is consistent with predictions of current models of bilingual processing, most paradigms used so far have mixed the two languages by using language ambiguous stimuli (e.g., cognates or interlingual homographs) or explicitly engaging the two languages because of experimental task requirements (e.g., word translation or language selection). These paradigms will have yielded different language processing contexts, the effect of which has seldom been taken into consideration. We propose that future studies should test the effect of language context on cross-language interactions in a systematic way, by controlling and manipulating the extent to which the experiment implicitly or explicitly prompts activation of the two languages.

Keywords: bilingual comprehension and production, language context, language selection and inhibition, cognate, inter-lingual homograph
How bilingual individuals process language is a long-standing topic for research in language science. A major discovery in the past decade is that when bilinguals use one language, information in the other language is also being accessed. Experimental psychology has established this phenomenon, known as cross-language interaction, during reading, listening, and speaking in bilinguals with various language combinations and levels of proficiency (see Kroll and De Groot, 2005, for a review). Consistent with behavioral evidence, results from event-related potential (ERP) studies have also shown parallel activation of lexical information from both languages (De Bruijn et al., 2001; Elston-Guttler et al., 2005; Rodriguez-Fornells et al., 2005; Kerkhofs et al., 2006). In the present article, we review studies which have used behavioral and electrophysiological measures with a focus on experimental paradigms that classically yield cross-language interactions. We believe that some of the paradigms adopted previously may have induced different language processing contexts because of the particular stimuli and tasks used, and that this could account for at least some of the discrepancies in the literature. More specifically, stimuli with a special status in the two languages of a bilingual speaker, such as cognates, and interlingual homographs, create a dual-language processing context which, despite their indisputable relevance as regards the process under study, raises the participants' explicit or implicit awareness of the bilingual context of testing. After selectively reviewing the literature, we argue that studies on cross-language interactions can and need to control the language context of the experiment (single/mixed language) prompted by the stimuli, tasks, and peripheral contextual cues.

\section{TESTING LANGUAGE PROCESSING IN BILINGUALS WITH TRANSLATION EQUIVALENTS}

A fundamental characteristic of bilingualism is the fact that a given semantic concept has at least two different lexical representations in the two languages. The most direct link between such two lexical representations in two given languages is called translation equivalence. For instance, the best translation of the word "train" in English is “火车” (pronounced as huo che) in Chinese. Late bilinguals, who acquired their second language (L2) after puberty, often develop their vocabulary in $\mathrm{L} 2$ by resorting to translation equivalents, i.e., through translation of L2 words in their first language (L1). Crosslanguage interactions between translation equivalents during word recognition in bilinguals have long been postulated in psycholinguistic models of bilingual processing. In the revised hierarchical model (RHM) for instance, Kroll and Stewart (1994) have argued that learners of an $\mathrm{L} 2$ rely on a lexical route through $\mathrm{L} 1$ translation equivalents to access meanings during word processing in L2. As learners become more proficient with their L2, independent and direct semantic links progressively develop between conceptual and lexical representations. A substantial number of studies have provided evidence that processing words in L2 activates translation equivalents in L1 (Potter et al., 1984; Keatley et al., 1994; BasnightBrown and Altarriba, 2007; e.g., Sanchez-Casas et al., 1992; for an exception see Scarborough et al., 1984; Sholl et al., 1995; Talamas et al., 1999). For instance, in a context of semantic priming, the recognition of a target word is facilitated not only when the prime word is semantically related to the target (e.g., "doctor-nurse") but even more so when the target is the translation equivalent of the prime (e.g., "doctor-arts", meaning doctor in Dutch) as compared to unrelated word pairs (e.g., doctor-fish; Kroll and Sholl, 1992; Tzelgov and Eben-Ezra, 1992; Keatley et al., 1994).

This special effect of translation equivalence has also been studied with ERPs, which are averaged brain waves recorded from the surface of the scalp time-locked to the onset of a stimulus of interest. The high temporal resolution of ERPs (millisecond range) makes them an ideal index of cognitive processing and particularly language processing as it unfolds in time (see Bentin et al., 1999 for 
a review). For instance, Alvarez et al. (2003) recorded ERPs in late English-Spanish bilinguals while they were engaged in a semantic categorization task on lexical items from their two languages ("press a button when the word refers to a part of the body in either language"). Critical items were repetitions both within (i.e., repetition priming) and across (translation priming) languages. As compared to the control condition in which the target word was preceded by an unrelated prime, translation priming modulated the N400 wave (an index of semantic integration (Kutas and Hillyard, 1980; Kutas and Hillyard, 1984). The reduction in N400 amplitude started earlier for L2 to L1 priming than the reverse, suggesting that processing a weaker language (L2) activates the translation equivalents in the stronger language (L1) to a greater extent than vice versa. However, the opposite trend in translation priming was observed in a more recent ERP study using masked semantic priming paradigm (Midgley et al., 2009). Using an auditory ERP paradigm, Phillips et al. (2006), presented translation equivalents following multiple, consecutive primes (e.g., bed, bed, bed, bed, and lit, the French translation of "bed"). Interestingly, ERP responses elicited by the release from adaptation in the L2-to-L1 direction were characterized by the presence of a phonological mismatch negativity (PMN, see Connolly and Phillips, 1994) and the absence of an N400. These findings tend to support that L1 translation phonology is not activated during L2 word processing (i.e., they lend support to the language-selective account).

Translation equivalence has also served as a context of choice in studies of word production in bilinguals. According to models of monolingual language production, speech planning begins with the activation/retrieval of conceptual representations that the speaker intends to convey, and through multiple cascading levels of processing ends up with the programming of mouth and tongue movement for articulation (Levelt, 1989). In the case of bilingual speakers, an additional level of processing has been proposed in which the target output language is determined (Kroll et al., 2006). Numerous studies have shown that, in the same vein as translation priming effects observed during word recognition, word production in bilinguals involves automatic access to translation equivalents in the non-target language (Hermans et al., 1998; Costa et al., 2000; Colome, 2001), despite the fact that word processing is arguably more under direct control of the speaker in terms of language selection as compared to the case of reading and listening. For instance, in a standard paradigm, the so-called picture-word interference paradigm, bilingual participants are required to name a picture which is superimposed or followed by a distractor word to be ignored (e.g., Costa et al., 1999; Hermans, 2004). Typically, when the distractor word is the translation equivalent of the target picture name, naming latency is shorter as compared to the case of unrelated distractor words in either of the two languages (Costa et al., 1999; Hermans, 2004). Moreover, an inhibitory effect (significantly longer reaction time) has been reported when the distractor word is phonologically related to the translation equivalent of the picture name (Hermans et al., 1998). These findings have been interpreted as evidence that speech planning in bilinguals involves activation of relevant information in both the languages. Crosslanguage activation of translation equivalents reduces the amount of semantic processing that is required for speech planning, hence produces a facilitation effect. The inhibitory effect prompted by distractor words which are phonologically related to the translation equivalent of the picture name suggests that translation priming exists not only at the semantic but also at the phonological level, where the phonotranslation distractor competes for lexical selection with the target word.

More recently, studies using ERPs have replicated and extended these behavioral findings (Guo and Peng, 2006; Chauncey et al., 2009). Specifically, naming pictures followed by the translation equivalents of their name in the non-target language, as compared to unrelated distractor words, induces N400 amplitude reductions. This cross-language priming effect is found both from L1 to L2 and from L2 to L1, despite the fact that the bilingual participants tested generally have various levels of proficiency in their two languages with different basic scripts (e.g., Chinese and English). In the case of more balanced bilinguals with more similar languages (e.g., French and English), cross-language priming effects were detected as early as $200 \mathrm{~ms}$ after stimulus onset. Both findings were interpreted as evidence for parallel activation of the two languages as a universal phenomenon underpinning bilingual speech production.

\section{THE LANGUAGE MODE HYPOTHESIS}

Studies in which translation equivalence was the critical experimental manipulation form a substantial fraction of the literature addressing word comprehension and production in bilinguals. Regardless of the type of measurement made (e.g., behavioral and ERPs), most of these studies have not considered the influences of the language processing context in which language non-selective access is observed. Beyond the issue of the artificiality inherent to experimental testing (e.g., requirement of participant attentional involvement and absence of irrelevant movements, controlled stimulus delivery, focus on single word processing, engagement in meta-linguistic tasks, etc.), the absence of consideration given to language mixing within a single experimental procedure raises questions. Unless the purpose is to understand the mechanisms underpinning language switching or translation (Crinion et al., 2006; Van Heuven et al., 2008), experimental paradigms that involve switching between two languages and/or test effects of translation equivalence raise the level of activation of the two languages and possibly prompt interactions that may not be significant otherwise. This issue becomes most salient when one considers the framework proposed in Grosjean's (2001) language mode hypothesis. Grosjean has proposed that a bilingual individual may be characterized by various states of L1 and L2 activation at a given point in time, a notion defined as the language mode continuum (Grosjean, 1985, $1994,1997,1998 b, 2001)$. Variables that may affect the language mode include language abilities of the interlocutor, the particular demands of a linguistic task, the purpose of the interaction, its topic, the contextual environment, and so on. The language mode is hypothesized to directly affect the level of activation of the bilingual's first and second languages and to interact with other factors that have an impact on bilingual's language processing mechanisms.

For instance, studies have shown that during a conversation, the interlocutors' understanding of language(s) and the topic affect the frequency and content of language mixing (e.g., code-switching and borrowing) in bilingual individuals (Grosjean, 1997; Treffers-Daller, 1997). This suggests that bilinguals consciously navigate along 
what Grosjean refers to as a "monolingual-bilingual continuum" to adjust levels of language of activation when producing speech. Furthermore, evidence of a recent comprehension study shows that changes in processing style induced by language context can be implicit (Cheng and Howard, 2008). Chinese-Taiwanese early bilinguals listened to language-mixed sentences while performing a synonymous judgment task or a semantic coherency task in Chinese. Results showed that a language switch cost was only observed when the participants were expecting the task to be monolingual (i.e., Experiment 1). When the task instructions and other experimental settings hinted that both languages might be involved in the experiment (i.e., Experiment 2), no switch cost was observed.

These findings suggest that the language context set explicitly or implicitly by the experiment may have a substantial effect on bilingual functioning. Disregarding such contextual effect may therefore have serious implications for the study of language selective/nonselective access in bilinguals. For instance, studies where translation equivalence was the critical manipulation (e.g., Alvarez et al., 2003) may not actively require translation from one language into the other but the use of a mixed-language design (e.g., semantic categorization in either language) and the long inter-stimuli intervals (e.g., $2.7 \mathrm{~s}$ ) enable participants to overtly translate each word before the onset of the next trial so as to achieve optimal performance. Consequently, the findings may be artificially biased toward parallel activation of L1 and L2 lexicons during word recognition. By contrast, in Phillips et al.'s (2006) study for instance, the prime word was repeatedly presented in one language leading to a relatively more monolingual context. Nevertheless, in the latter study, the use of interlingual homographs such as "lit" (meaning bed in French) may also have artificially raised the level of activation of French even though participants were tested in an "English-only" context, simply because participants are likely to spot the critical interlingual homographs throughout the experiment (see section Interlingual Homographs).

Other evidence comes from studies using highly similar contexts and conducted in the same sensory modality. In an eye-tracking study, Spivey and Marian (1999; ) also see Marian and Spivey, 2003) obtained evidence for cross-language interference in RussianEnglish bilinguals who spent more time looking at objects that have overlapping initial phonetic features in Russian and English (e.g., "marka" in Russian for "marker") upon hearing an interlingual distractor, in a Russian session of the experiment (i.e., when English was the non-target language). In the English session, the cross-language interaction was only seen as a trend (i.e., no L1 to L2 effect). However, despite the claim that this effect was observed "without actually compromising the monolingual speech mode" (p. 281), a subsequent study by the same authors reported the opposite pattern of results with the same design and tasks (Marian and Spivey, 2003). A critical difference between the two studies was that, in the first, the same participants were tested in both the Russian and the English sessions and, consequently, they were fully aware of the bilingual nature of the study. The second study, by contrast, used separate groups of participants who were led to believe that they participated in a monolingual experiment.

More recent results further suggest that language context effects on dual-language activation interact with a bilingual's age of acquisition in L2 (Canseco-Gonzalez et al., 2010). In an eye-tracking experiment, Spanish-English bilinguals were tested in three language mode conditions. While the bilingual mode condition increased the size of cross-language interference as compared to the monolingual mode condition in both early and late bilinguals, only participants who acquired L2 before the age of 6 showed a significant effect of language mode.

While it is not possible to evaluate whether language processing context effects account for discrepancies between previous findings, as argued in the language mode hypothesis, we believe it invites caution in the interpretation of results from studies involving mixed-language conditions. The criticism is that, unless it is controlled or deliberately manipulated, language context is a potentially confounding variable when examining the selectivity of language processing in bilinguals because it is closely related and critical to the theoretical issue under investigation.

\section{TESTING BILINGUALS WITH INTERLINGUAL HOMOGRAPHS: ALL-IN-L2?}

In alphabetical languages that share the same or similar scripts, some words share properties across languages, such as spelling (homographs; e.g., "brand" which means "fire" in Dutch), sound (homophones; e.g., "cinq" which sounds like "sank" in English, but means "five" in French), and/or meaning (cognates; e.g., "café", which has the same meaning in several European languages). Previous studies have provided evidence that the interlingual status of cognates and homographs affect bilingual performance in word recognition and production (see Costa et al., 2005 and Dijkstra, 2005 for a review, respectively). For instance, Beauvillain and Grainger (1987) tested French-English bilinguals in a lexical decision task (LDT). In each trial, English target words were presented following French prime words which, in the critical condition, were interlingual homographs related in meaning with the English target word (e.g., coin - money, coin meaning "corner" in French). Although they were told that the French prime was irrelevant, participants spontaneously accessed the English meaning of homograph primes as shown by significantly reduced reaction time in the related as compared to the unrelated condition. Numerous studies have also demonstrated that even in LDT on words exclusively in L2 (i.e., in an "all-in-L2" context), bilingual performance on homographs and cognates is influenced by their meaning in the non-target language (Dijkstra et al., 1998; De Groot et al., 2000; Van Hell and Dijkstra, 2002; Lemhofer and Dijkstra, 2004).

Interlingual stimuli have been shown to have a special status also in ERP studies. Using a similar semantic priming paradigm as that used by Beauvillain and Grainger (1987), Kerkhofs et al. (2006) found a reduction in reaction time and N400 amplitude when Dutch-English bilinguals performed an LDT on homographs (e.g., stem meaning "voice" in Dutch) preceded by semantically related primes (e.g., root). Both the ERP and the behavioral effects were also correlated with the relative lexical frequencies of the homographs across languages, such that the response times and N400 amplitude were reduced with increasing lexical frequency in English and decreasing frequency in Dutch. These findings replicated previous studies using behavioral measures and have been put forward as evidence for automatic L1 access during $\mathrm{L} 2$ reading in bilinguals. 
Studies of bilingual word production using the picture naming paradigm have shown facilitation (shorter reaction times) when the name of the picture to be named is a cognate as compared to a non-cognate (Costa et al., 2000, 2006; Hoshino and Kroll, 2005). For instance, a recent study of picture naming has found a reduction in ERP amplitude between 300 and 400 ms correlated with the cognate facilitation effect in behavioral measurements (Christoffels, et al., 2007). In the same vein as interlingual homograph effects in word recognition, this cognate facilitation effect in production has been taken as evidence that information in the unintended language is activated during the planning of speech in the target language. However, there is as yet no consensus regarding the specific locus of this effect because cognates share across languages several levels of representations (e.g., semantic, phonological, and orthographic).

Although it can be argued that studies using interlingual stimuli are less readily perceived as bilingual than studies explicitly mixing two languages (as in language switch and translation experiments), there is evidence that bilinguals' responses to interlingual stimuli are influenced by language context. For example, Dijkstra et al. (1998) tested Dutch-English bilinguals reading English words and nonwords intermixed with English/Dutch homographs and cognates. In one experiment (i.e., Experiment 1), participants were asked to perform a LDT in English (i.e., indicate whether each item was a word of English or a non-word). Cognates, but not homographs, elicited a faster response than control items. In another experiment (i.e., Experiment 3), participants were presented with the same set of stimuli and were asked to do a generalized LDT instead (i.e., indicate whether each item was either a word in English or Dutch or a non-word). Interestingly, a homograph effect was found in this experiment such that homographs were responded to more quickly only when compared to English control words but not to Dutch words. These results are consistent with an effect of language context on the processing on interlingual stimuli. When the task required the activation of lexical representations in one language only as in Experiment 1, the activation level of Dutch (i.e., the non-target language) was arguably insufficient for homograph representations to be activated through lexical links with English, whereas the activation of cognate representations benefited from both lexical and semantic links across languages. In Experiment 3, the generalized LDT required participants to access representations in both their languages. Therefore, Dutch-English bilinguals were more likely to consider homographs as Dutch words and responded equally fast to homographs and Dutch control words. This explains the significant difference between the homograph and the English word conditions, English being the weaker language of the participants.

Dijkstra et al.'s (1998) study shows that cognitive demands can influence bilingual's processing of interlingual stimuli through manipulation of language context using different tasks. In fact, the potential role of language context is delicate to discuss when the experiment involves interlingual stimuli and yet the task requires access to representations in only one language (i.e., Experiment 1). The question is, when stimuli and task requirements are supposed to tap into only one language (e.g., all-in-L2), whether the context can be considered de facto monolingual despite the fact that some of the stimuli also exist in the other language. However, the repeated occurrence (e.g., 33\% or 50\%) of stimuli that also have a meaning in the non-target language may lead participants to activate the other language - either consciously or unconsciously - and eventually operate a transition to a more or less dual-language processing context as the experiment unfolds. This is more likely to be true in highly proficient bilinguals who are particularly wary about interlingual homographs, because they are a source of confusion/surprise in everyday language use. Furthermore, post experiment debriefing is not used routinely to evaluate whether participants become overtly aware about the special status of critical stimuli in such experiments.

Consistent with this view, several studies have demonstrated that the effects of interlingual stimuli is modulated by the language context even when the experimental task is monolingual (ElstonGuttler et al., 2005; Christoffels et al., 2007; Elston-Guttler and Gunter, 2008; ). but see also Paulmann et al., 2006). For instance, A 20-min pre-experiment film narrated in English enabled a group of German-English bilinguals to find themselves in an "all-L2" context whereby the effect of L1 on L2 mediated by interlingual homographs was minimal, contrasting with the clear interlingual homograph effect seen when the pre-experiment film was in German (Elston-Guttler et al., 2005). Similarly, the auditory presentation of German words and even pseudowords enhanced the German-English homograph effects in a visual experiment where participants were instructed to read English words (ElstonGuttler and Gunter, 2008).

It must be noted at this point that a number of studies have investigated the processing of cognates and interlingual homographs within sentences setting out a language context. Findings from these studies suggest that although sentence context may not fully eliminate the processing advantages of cognates, it can modify both the degree and the level of the effects. For example, in the case of highly semantically constrained sentences, cognate effects are either reduced (Libben and Titone, 2009) or appear to be absent as compared to sentences with low semantic constraints (Van Hell and de Groot, 2008). Furthermore, sentence context has also been shown to dissociate the effects of cognates from interlingual homographs: cognate effects are more resilient than homograph effects when critical words are processed in sentences (Schwartz and Kroll, 2006; Schwartz and Arêas da Luz Fontes, 2008;). but also see Duyck et al., 2007). The difference between cognate (i.e., sharing both semantic and lexical representations between languages) and interlingual homograph (i.e., sharing only lexical representations) effects suggests that language non-selectivity is more salient at the semantic than the lexical level. Since word recognition differs primarily at the lexical level between monolinguals and bilinguals, sentence context effects on interlingual homograph processing cannot be simply accounted for by the mechanisms underlying within-language ambiguity resolution.

\section{CONCLUSION AND PERSPECTIVES}

Experimental psychology and electrophysiology have made the case for automatic co-activation of the two languages of bilingual individuals when they are expected to function in one of their languages. Here, we reviewed two main types of experiments, involving translation equivalence and interlingual stimuli, and argued that the cognitive processing impact of the language context has generally been overlooked. We argue that both in language production and comprehension, bilingual individuals can manifest varying levels of baseline activation of their two languages. For a systematic 
control of language context as a potentially confounding variable, and also to further investigate the role of the language context as an independent variable, we suggest that future studies on bilingual language interaction should consider the following questions:

1. Do the experimental tasks require explicit retrieval of representations from one or two languages?

2. Does the experiment involve stimuli (e.g., words or grammatical constructs) from the two languages or stimuli that are language ambiguous? For instance, the issue of cognate facilitation is virtually totally absent in the case of Western-Asian language pairs (with the exception of borrowings).

3. Are the two languages of the bilingual population under study sufficiently dissimilar to consider that participants may be functioning monolingually (i.e., Chinese-English bilingual speakers may function monolingually in English, in theory, but Chinese-Japanese bilinguals may never do so in Japanese due to large overlaps between the two languages)? In particular, is the orthographic transparency of the two languages different? How wide is phonological overlap between them? etc.

4. Is the performance of bilingual participants in the two languages compared within (potential carry over/order effects) or across (independence but reduced power) groups?

5. Are bilingual participants debriefed after the experiment regarding their awareness of the bilingual/monolingual nature of the experiment?

6. Is there any other contextual information that might draw the participants' attention to one language in particular (e.g., laboratory settings, language of instruction, native language of the experimenter, and so on)?

7. For experiments that are concerned with more than one of the factors listed above, how do these factors interact with one another?

Grosjean $(2001,2008)$ has compiled several lists of such variables, which might influence bilinguals' language mode in a general sense. However, these conditions are so varied that it is impossible to create a pure monolingual or a perfectly balanced bilingual

\section{REFERENCES}

Alvarez, P. R., Holcomb, P. J., and Grainger, J. (2003). Accessing word meaning in two languages: an event-related brain potential study of beginning bilinguals. Brain Lang. 87, 290-304.

Basnight-Brown, D. M., and Altarriba, J. (2007). Differences in semantic and translation priming across languages: the role of language direction and language dominance. Mem. Cogn. 35, 953-965.

Beauvillain, C., and Grainger, J. (1987). Accessing interlexical homographs: some limitations of a languageselective access. J. Mem. Lang. 26, 658-672.

Bentin, S., Mouchetant-Rostaing, Y., Giard, M. H., Echallier, J. F., and Pernier, J. (1999). ERP manifestations of processing printed words at

experimental context ${ }^{1}$ (also see Dijkstra et al., 2003 for the same consideration). Our proposal highlights factors that are particularly important for studies concerned with the activation levels of the two languages (i.e., selective versus non-selective accounts of lexical access). We believe it is important for future studies to weight the individual and combined effects of these factors on bilingual processing, not only to further our understanding of language nonselectivity, but also to shed light on the difference in architecture between the bilingual and the monolingual language systems.

Beyond this methodological issue, devoting particular attention to language contextual effects will contribute to the theoretical development of bilingual models. So far, evidence for parallel language activation has been consistent with the assumption that, during the initial stages of word processing, lexical candidates in both the bilingual's languages are automatically activated even when access to only one language is required. Prominent psycholinguistic models propose that a top-down control mechanism enables bilingual individuals to function in the target language by inhibiting lexical candidates from the non-target language (Grainger and Dijkstra, 1992; Dijkstra and Van Heuven, 1998; Green, 1998). While the locus of such inhibitory control is still under investigation, evidence of language contextual effects may need to be elucidated and incorporated to current models as "language nodes". The language nodes are expected to be sensitive to external sources of information (i.e., bottom-up influences) as well as the bilingual speaker's explicit intention (i.e., top-down control). As a determinate of bilingual's language processing, language nodes would preset the activation levels of the two languages prior to functioning (e.g., in the beginning of an experiment) and monitor language activation online. Such an activation-based mechanism should not be perceived as incompatible with inhibitory control and bringing the two theoretical principles together is likely to account for the contextual effects on bilingual functioning reported so far.

${ }^{1}$ Indeed, as Grosjean (1998a) puts it: "simply knowing that there is a possibility that elements from the other language will be presented (in an experiment, for example) will move the bilingual away from the monolingual endpoint of the continuum. Just one guest word in a stream of base language words can increase this displacement toward the bilingual endpoint." (p. 137).

Colome, A. (2001). Lexical activation in bilinguals' speech production: language-specific or language-independent? J. Mem. Lang. 45, 721-736.

Connolly, J. F., and Phillips, N., A. (1994). Event-related potential components reflect phonological and semantic processing of the terminal word of spoken sentences. J. Cogn. Neurosci. 6, 256-266.

Costa, A., Caramazza, A., and SebastianGalles, N. (2000). The cognate facilitation effect: implications for models of lexical access. J. Exp. Psychol. Learn. Mem. Cogn. 26, 1283-1296.

Costa, A., La Heij, W., and Navarrete, E. (2006). The dynamics of bilingual lexical access. Biling: Lang. Cogn. 9, 137-151.

Costa, A., Miozzo, M., and Caramazza, A. (1999). Lexical selection in bilinguals: do words in bilingual's two lexicons compete for selection? J. Mem. Lang. 41, 365-397.

Costa, A., Santesteban, M., and Cano, A. (2005). On the facilitatory effects of cognate words in bilingual speech production. Brain Lang. 94, 94-103.

Crinion, J., Turner, R., Grogan, A., Hanakawa, T., Noppeney, U., Devlin, J. T., Aso, T., Urayama, S., Fukuyama, H., Stockton, K., Usui, K., Green, D. W., and Price, C. J. (2006). Language control in the bilingual brain. Science 312, 1537-1540.

De Bruijn, E. R.A., Dijkstra, T., Chwilla, D. J., and Schriefers, H. (2001). Language context effects on interlingual homograph recognition: evidence from event-related potentials and response times in semantic priming. Biling: Lang. Cogn. 4, 155-168. 
De Groot, A. M. B., Delmaar, P., and Lupker, S. J. (2000). The processing of interlexical homographs in translation recognition and lexical decision: support for non-selective access to bilingual memory. Q. J. Exp. Psychol. 53, 397-428.

Dijkstra, T., and Van Heuven, W. J. B. (1998). "The BIA model and bilingual word recognition," in Localist Connectionist Approaches to Human Cognition, eds J. Grainger and A. M. Jacobs (Hillsdale, NJ: Lawrence Erlbaum Associates), 189-225.

Dijkstra, T. (2005). "Bilingual visual word recognition and lexical access," in Handbook of Bilingualism: Psycholinguistic Approaches, eds J. F. Kroll and A. De Groot (New York: Oxford University), 178-201.

Dijkstra, T., and Van Hell, J. (2003). Testing the language mode hypothesis using trilinguals. Int. J. Biling. Educ. Biling. 6, 2-16.

Dijkstra, T., Van Jaarsveld, H., and Ten Brinke, S. (1998). Interlingual homograph recognition: effects of task demands and language intermixing. Biling: Lang. Cogn. 1, 51-66.

Duyck, W., Van Assche, E., Drieghe, D., and Hartsuiker, R. (2007). Visual word recognition by bilinguals in a sentence context: evidence for nonselective lexical access. J. Exp. Psychol. Learn. 33, 663-679.

Elston-Guttler, K. E., and Gunter, T. (2008). Fine-tuned: phonology and semantics affect first- to second-language zooming in. J. Cogn. Neurosci. $21,1-17$.

Elston-Guttler, K. E., Gunter, T. C., and Kotz, S. A. (2005). Zooming into L2: global language context and adjustment affect processing of interlingual homographs in sentences. Brain Res. Cogn. Brain Res. 25, 57-70.

Grainger, J., and Dijkstra, T. (1992). “On the representation and use of language information in bilinguals," in Cognitive Processing in Bilinguals, ed R. J. Harris (Amsterdam: Elsevier), 207-220.

Green, D. W. (1998). Mental control of the bilingual lexico-semantic system. Biling: Lang. Cogn. 1, 67-81.

Grosjean, F. (1985). The bilingual as a competent but specific speaker-hearer. JMMD 6, 467-477.

Grosjean, F. (1994). "Individual bilingualism," in The Encyclopedia of Language, ed R. R. Asher (Oxford: Pergamon Press), 1656-1660.

Grosjean, F. (1997). "Processing mixed language: issues, findings and models," in Tutorials in Bilingualism: Psycholinguistic Perspectives, eds A. M. B. De Groot and J. F. Kroll (Mahwah, NJ: Lawrence Erlbaum Associates), 225-254.
Grosjean, F. (1998a). Studying bilingualism: methodological and conceptual issues. Biling: Lang. Cogn. 1, 131-149.

Grosjean, F. (1998b). Transfer and language mode. Biling: Lang. Cogn. 1, 175-176.

Grosjean, F. (2001). “The bilingual's language modes," in One mind, Two languages: Bilingual Language Processing, ed L. N. Janet (Oxford: Blackwell), $1-22$.

Grosjean, F. (2008). Studying Bilinguals. Oxford: Oxford University Press.

Guo, T., and Peng, D. (2006). Event-related potential evidence for parallel activation of two languages in bilingual speech production. Neuroreport 17, 1757-1760.

Hermans, D. (2004). Between-language identity effects in picture-word interference tasks: a challenge for languagenonspecific or language-specific lexical access? Int. J. Biling 8, 115-125.

Hermans, D., Bongaerts, T., de Bot, K., and Schreuder, R. (1998). Producing words in a foreign language: Can speakers prevent interference from their first language? Biling: Lang. Cogn. 1, 213-229.

Hoshino, N., and Kroll, J. F. (2005). Cognate Effect in Picture Naming: Does Cross-Language Activation Survive a Change of Script? Paper presented at Fifth International Symposium on Bilingualism, Barcelona, Spain.

Keatley, C., Spinks, J., and De Gelder, B. (1994). Asymmetrical semantic facilitation between languages. Mem. Cogn . 22, 70-84.

Kerkhofs, R., Dijkstra, T., Chwilla, D. J. and de Bruijn, E. R. (2006). Testing a model for bilingual semantic priming with interlingual homographs: RT and N400 effects. Brain Res. 1068, 170-183.

Kroll, J. F., Bobb, S. C., and Wodniecka, Z. (2006). Language selectivity is the exception, not the rule: arguments against a fixed locus of language selection in bilingual speech. Biling: Lang. Cogn. 9, 119-135.

Kroll, J. F., and De Groot, A. M. B. (2005). Handbook of Bilingualism: Psycholinguistic Approaches. New York, Oxford University Press.

Kroll, J. F., and Sholl, A. (1992). "Lexical and conceptual memory in fluent and nonfluent bilinguals," in Cognitive Processing in Bilinguals, ed R. J. Harris (Amsterdam: Elsevier), 191-204.

Kroll, J. F., and Stewart, E. (1994). Category interference in translation and picture naming: evidence for asymmetric connections between bilingual memory representations. J. Mem. Lang. 33, 149-174.

Kutas, M., and Hillyard, S. A. (1980). Reading senseless sentences: brain potentials reflect semantic incongruity. Science 207, 203-205.

Kutas, M., and Hillyard, S.A. (1984). Brain potentials during reading reflect word expectancy and semantic association. Nature 307, 161-163.

Lemhofer, K., and Dijkstra, T. (2004). Recognizing cognates and interlingua homographs: effects of code similarity in language specific and generalized lexical decision. Mem. Cogn. 32, 533-550.

Levelt, W. J. (1989). Speaking: From Intention to Articulation. Cambridge, MA, MIT Press.

Libben, M. R., and Titone, D. A. (2009) Bilingual lexical access in context: Evidence from eye movements during reading. J. Exp. Psychol. Learn. 35, 381-390.

Marian, V., and Spivey, M. (2003). Competing activation in bilingual language processing: within- and between-language competition. Biling: Lang. Cogn. 6, 97-115.

Midgley, K. J., Holcomb, P. J., and Grainger J. (2009). Masked repetition and translation priming in second language learners: a window on the time-course of form and meaning activation using erps. Psychophysiology 46, 551-565.

Paulmann, S., Elston-Guttler, K. E., Gunter, T. C., and Kotz, S.A. (2006). Is bilingual lexical access influenced by language context? Neuroreport 17, 727-731.

Phillips, N. A., Klein, D., Mercier, J., and de Boysson, C. (2006). ERP measures of auditory word repetition and translation priming in bilinguals. Brain Res. 1125, 116-131.

Potter, M. C., So, K.-F., Von Eckardt, B. and Feldman, L. B. (1984). Lexical and conceptual representation in beginning and proficient bilinguals. J. Verb. Learn. Verb. Behav. 23, 23-38.

Rodriguez-Fornells, A., van der Lugt, A., Rotte, M., Britti, B., Heinze, H. J., and Munte, T. F. (2005). Second language interferes with word production in fluent bilinguals: brain potential and functional imaging evidence. J. Cogn. Neurosci. 17, 422-433.

Sanchez-Casas, R. M., Suarez-Buratti, B. and Igoa, J. M. (1992). Are Bilingual Lexical Representations Interconnected? Paper presented at: Fifth conference of the European Society for Cognitive Psychology, Paris.

Scarborough, D. L., Gerard, L., and Cortese, C. (1984). Independence of lexical access in bilingual word recognition. J. Verb. Learn. Verb. Behav. 23, 84-99.

Schwartz, A. I., and Kroll, J. F. (2006). Bilingual lexical activation in sentence context. J. Mem. Lang. 55, 197-212.

Schwartz, A. I., and Arêas da Luz Fontes, A. (2008). Cross-language mediated priming: effects of context and lexical relationship. Biling: Lang. Cogn. 11, 95-110.

Sholl, A., Sankaranarayana, A., and Kroll, J. F. (1995). Transfer between picture naming and translation: a test of asymmetries in bilingual memory. Psychol. Sci. 6, 45-49.

Spivey, M. J., and Marian, V. (1999). Cross talk between native and second languages: partial activation of an irrelevant lexicon. Psychol. Sci. 10, 281-284.

Talamas, A., Kroll, J. F., and Dufour, R. (1999). Form related errors in second language learning: a preliminary stage in the acquisition of L2 vocabulary. Biling: Lang. Cogn. 2, 45-58.

Treffers-Daller, J. (1997). "Variability in code-switching styles: TurkishGerman code-switching patterns," in Code-Switching Worldwide, ed R. Jacobson (Berlin: Mouton de Gruyter), 177-197.

Tzelgov, J., and Eben-Ezra, S. (1992). Components of the between-language semantic priming effect. Eur. J. Cogn. Psychol. 4, 253-272.

Van Hell, J. G., and Dijkstra, T. (2002). Foreign language knowledge can influence native language performance in exclusively native contexts. Psychon. Bull. Rev. 9, 780-789.

Van Hell, J. G., and de Groot, A. M. B. (2008). Sentence context affects lexical decision and word translation. Acta Psychol. 128, 431-451.

Van Heuven, W. J. B., Schriefers, H., Dijkstra, T., and Hagoort, P. (2008). Language conflict in the bilingual brain. Cereb. Cortex 18, 2706-2716.

Conflict of Interest Statement: The authors declare that this manuscript was prepared in the absence of any commercial and financial relationships that could be constructed as a potential conflict of interests.

Received: 24 March 2010; accepted: 07 October 2010; published online: 01 November 2010.

Citation: $W u$ Y J and Thierry G (2010). Investigating bilingual processing: the neglected role of language processing contexts. Front. Psychology 1:178. doi: 10.3389/ fpsyg. 2010.00178

This article was submitted to Frontiers in Language Sciences, a specialty of Frontiers in Psychology.

Copyright: (c) 2010 Wu and Thierry. This is an open-access article subject to an exclusive license agreement between the authors and the Frontiers Research Foundation, which permits unrestricted use, distribution, and reproduction in any medium, provided the original authors and source are credited. 